\title{
Optimizing lung aeration at birth using a sustained inflation and positive pressure ventilation in preterm rabbits
}

\author{
Arjan B. te Pas ${ }^{1,2}$, Marcus J. Kitchen ${ }^{3}$, Katie Lee ${ }^{3}$, Megan J. Wallace ${ }^{2}$, Andreas Fouras ${ }^{4,5}$, Robert A. Lewis ${ }^{4,6}$, Naoto Yagi ${ }^{7}$, \\ Kentaro Uesugi ${ }^{7}$ and Stuart B. Hooper ${ }^{2}$
}

BACKGROUND: A sustained inflation (SI) facilitates lung aeration, but the most effective pressure and duration are unknown. We investigated the effect of gestational age (GA) and airway liquid volume on the required inflation pressure and SI duration.

METHODS: Rabbit kittens were delivered at 27, 29, and $30 \mathrm{~d}$ gestation, intubated and airway liquid was aspirated. Either no liquid (control) or $30 \mathrm{ml} / \mathrm{kg}$ of liquid was returned to the airways. Lung gas volumes were measured by plethysmography and phase-contrast X-ray-imaging. Starting at $22 \mathrm{cmH}_{2} \mathrm{O}$, airway pressure was increased until airflow commenced and pressure was then held constant. The SI was truncated when $20 \mathrm{ml} / \mathrm{kg}$ air had entered the lung and ventilation continued with intermittent positive pressure ventilation (iPPV).

RESULTS: Higher SI pressures and longer durations were required in 27-d kittens compared to 30-d kittens. During iPPV, 27-d kittens needed higher pressures and had lower functional residual capacity (FRC) compared to 30-d kittens. Adding lung liquid increased SI duration, reduced FRC, and increased resistance and pressures during iPPV in 29- and 30-d kittens.

CONCLUSION: Immature kittens required higher starting pressures and longer SI durations to achieve a set inflation volume. Larger airway liquid volumes adversely affected lung function during iPPV in older but not young kittens.

$\mathbf{T}$ he use of an initial sustained inflation (SI) has recently been reinvestigated with the aim of providing sufficient time for the air/liquid interface to move into the distal airways before commencing tidal ventilation $(1,2)$. Experimental studies have shown that an initial SI at birth has beneficial effects on lung aeration, lung mechanics, and pulmonary blood flow (1-4) without increasing the risk of injury $(5,6)$.

Despite the experimental studies, it is not clear what inflation pressure should be used and how long the inflation should be maintained to achieve uniform lung aeration without overinflating and injuring lung regions. There is no data to support the length of the initial inflations recommended in current resuscitation guidelines $(7,8)$. Although SIs of different durations and inflation pressures have been investigated in clinical studies with varying success (9-13), these studies provide little information on the optimal duration and inflation pressure that should be used and the factors influencing this.

Gestational age (GA)-related reductions in airway dimensions (airway diameter, surface area) must increase the resistance and, therefore, the inflation pressures required to move liquid through the airways in younger preterm infants. Furthermore, the volume of airway liquid present at ventilation onset will likely vary between infants and, if high, then larger liquid volumes must be moved through the airways. However, it is not known whether larger volumes influence the required inflation pressure or duration of an SI or whether the larger volumes influence ventilation during the immediate newborn period.

Our aim was to determine the effect of GA and the volume of airway liquid on the pressure needed to begin lung aeration, the rate of lung aeration and the duration of the SI required to achieve a set inspired volume. We have also investigated the effect on respiratory function parameters during both the SI and the subsequent period of intermittent positive pressure ventilation (iPPV).

\section{RESULTS}

\section{Animal Data}

In total, 42 newborn preterm rabbit kittens were ventilated from birth; 16 kittens at $27 \mathrm{~d}, 12$ at $29 \mathrm{~d}$, and 14 at $30 \mathrm{~d}$ GA. Mean $( \pm$ SEM) kitten weight was not different between $29(37.6 \pm 7.0 \mathrm{~g})$ and $30 \mathrm{~d}(38.6 \pm 3.0 \mathrm{~g}$; ns), but was significantly lower at $27 \mathrm{~d}$ GA $(25.2 \pm 3.6 \mathrm{~g} ; P<0.01)$. At each GA, the mean kitten weights between the two experimental groups were not different (ns) and no kittens developed pneumothoraxes.

\section{Starting Pressure and Duration of SI}

Effect of GA. In the liquid added groups, $27 \mathrm{~d}$ GA kittens needed a higher inflation pressure $\left(36 \pm 1 \mathrm{cmH}_{2} \mathrm{O} ; P<0.001\right)$

\footnotetext{
'Division of Neonatology, Department of Pediatrics, Leiden University Medical Center, Leiden, the Netherlands; ${ }^{2}$ The Ritchie Center, Monash institute for Medical Research, Monash University, Victoria, Australia; ${ }^{3}$ School of Physics and Astronomy, Monash University, Victoria, Australia; ${ }^{4}$ Department of Medical Imaging and Radiation Sciences, Monash University, Victoria, Australia; ${ }^{5}$ Department of Mechanical and Aerospace Engineering, Monash University, Victoria, Australia; ${ }^{6}$ Department of Medical Imaging, University of Saskatchewan, Saskatoon, Saskatchewan, Canada; ${ }^{7} J a p a n$ Synchrotron Radiation Research Institute, Hyogo, Japan. Correspondence: Arjan B. te Pas (a.b.te_pas@lumc.nl) Received 14 September 2015; accepted 11 January 2016; advance online publication 13 April 2016. doi:10.1038/pr.2016.59
} 


\section{Articles $\mid$ te Pasetal.}

before air started to move into the lung (starting pressure) compared with both older groups; the required starting pressure was not different between $29 \mathrm{~d}\left(30 \pm 1 \mathrm{~cm} \mathrm{H}_{2} \mathrm{O}\right)$ and 30 d GA $\left(29 \pm 0 \mathrm{cmH}_{2} \mathrm{O}\right)$ kittens (Table 1; Figure 1a). The 27-d

Table 1. Mean (SEM) starting pressure, duration, and end-volume of SI

\begin{tabular}{llccc}
\hline GA (days) & Lung liquid & $\begin{array}{c}\text { Starting pressure } \\
\left(\mathrm{cmH}_{2} \mathrm{O}\right)\end{array}$ & $\begin{array}{c}\text { Sl duration } \\
\text { (seconds) }\end{array}$ & $\begin{array}{c}\text { Vol at end } \\
\mathrm{SI}(\mathrm{ml} / \mathrm{kg})\end{array}$ \\
\hline 27 & Added & $36(1)^{*}$ & $46(3)$ & $20.7(0.3)$ \\
& Control & $37(1)^{*}$ & $44(3)^{*}$ & $21.3(0.5)$ \\
29 & Added & $30(1)$ & $39(5)$ & $20.3(0.2)$ \\
& Control & $28(1)$ & $26(5)$ & $18.9(2.4)$ \\
30 & Added & $29(1)$ & $38(9)$ & $19.4(1.2)$ \\
& Control & $27(1)$ & $29(7)$ & $23.0(1.0)$ \\
\hline
\end{tabular}

${ }^{*} P<0.00127$ vs. 29 and $30 \mathrm{~d}$ GA.

GA, gestational age; SI, sustained inflation.

a

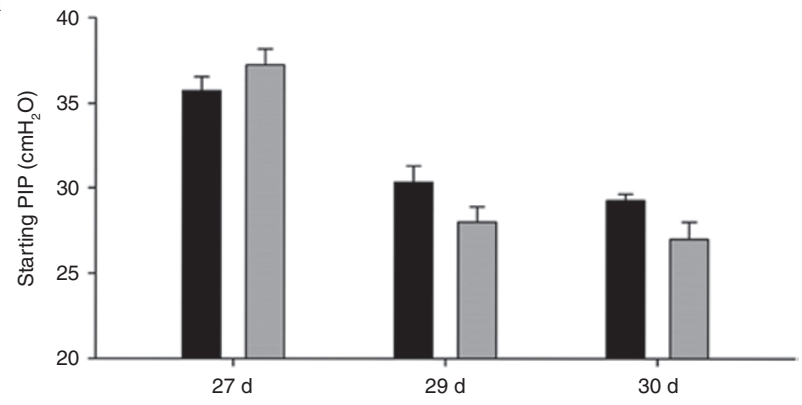

b

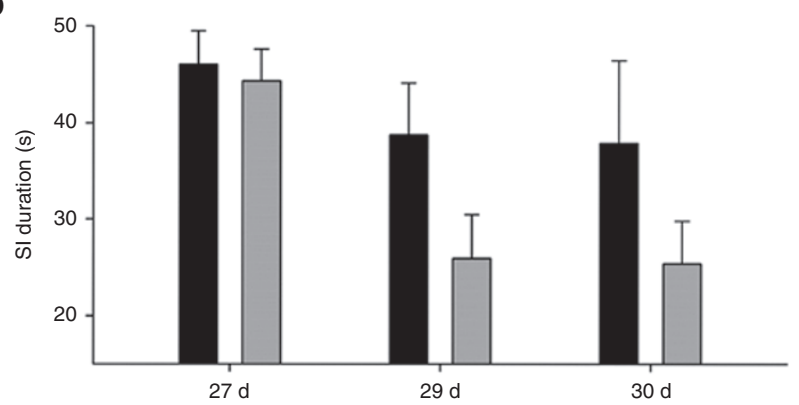

C

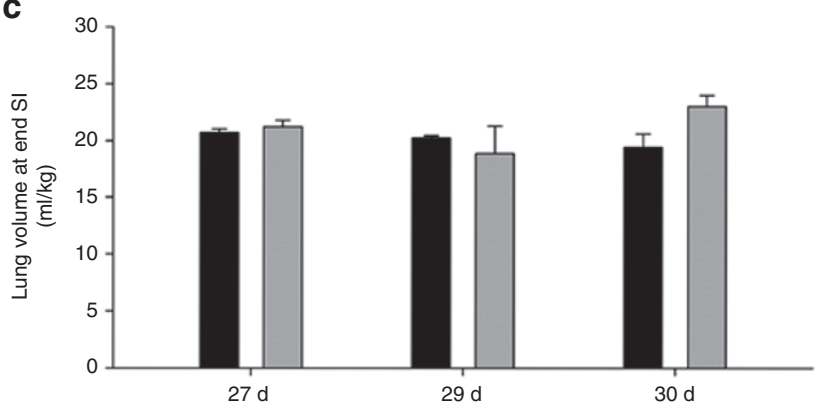

Figure 1. Peak inflating pressure at which air commenced flowing into the lung (starting peak inspiratory pressure) (a), the duration (b), and the lung volume achieved (c) during a sustained inflation (SI) in newborn rabbits delivered at 27, 29, and $30 \mathrm{~d}$ of gestational age (GA). At each GA, airway liquid was gently aspirated and either a set volume of liquid $(30 \mathrm{ml} /$ $\mathrm{kg}$ ) was returned to the lung (liquid added; black) or the liquid was not replaced (control, gray). kittens also tended to need a longer SI duration $(46 \pm 3 \mathrm{~s})$ at a higher pressure (Supplementary Movie S1 online) compared with the older kittens, but this difference was not significant between $29 \mathrm{~d}(39 \pm 5 \mathrm{~s})$ (Supplementary Movie S2 online) and $30 \mathrm{~d}$ GA (38 \pm 9 s) kittens (Supplementary Movie S3 online) (Table 1; Figure 1b).

In the control groups, the $27 \mathrm{~d}$ GA kittens also needed a higher starting pressure $\left(37 \pm 1 \mathrm{cmH}_{2} \mathrm{O} ; P<0.001\right)$ and longer duration $(44 \pm 3 \mathrm{~s} ; P<0.001)$ compared to both older groups (Table 1, Figure 1a,b), but there was no significant difference in starting pressure $\left(28 \pm 1\right.$ and $\left.27 \pm 1 \mathrm{cmH}_{2} \mathrm{O}\right)$ and SI duration ( $26 \pm 5$ and $25 \pm 4$ s) between 29 and $30 \mathrm{~d}$ GA kittens, respectively (Table 1; Figure 1a,b).

Effect of lung liquid volume. At each GA, there were no significant differences in starting pressure and duration of the SI between lung liquid added and control groups, although SI duration tended to be shorter in the control group at both 29 and $30 \mathrm{~d}$ GA compared to the liquid-added groups (Table 1; Figure 1a,b).

The gas volume of the lung (in $\mathrm{ml} / \mathrm{kg}$ ) achieved during the SI was similar in all groups and at all GAs (Table 1; Figure 1c).

\section{Lung Inflation Rate and Resistance}

Effect of GA. The inflation rate during the SI tended to increase with GA in both groups, although this was not significant most likely because of the different inflation pressures (Table 2; Figure 2a). Indeed, the resistance to liquid flow during the SI was significantly $(P<0.05)$ decreased with increasing GA in both groups (Table 2; Figure 2b). At mid-iPPV in the control group, the inflation rate was slower $(P<0.05)$ and the resistance was higher $(P<0.01)$ at $27 \mathrm{~d}$ compared to 29 and $30 \mathrm{~d}$ GA (Table 2; Figure 2c,d). However, no differences between GAs were observed between the liquid-added groups (Table 2; Figure 2c,d).

Effect of lung liquid volume. The inflation rate and resistance during the SI were not different between the liquidadded and control groups at all GAs (Table 2; Figure 2a,b). However, at mid-iPPV, the inflation rate was considerably higher $(P<0.01)$ and resistance lower $(P<0.01)$ in the control group compared to the liquid-added groups at 29 and 30 d GA (Table 2; Figure 2c,d).

\section{FRC and PIP}

Effect of GA. The FRC at the end of the SI was similar at each GA in the liquid added groups, but was significantly increased with increasing GA $(P<0.01)$ in the control group (Table 3; Figure 3a). With increasing GA, the FRC measured at midiPPV increased in the liquid-added (27 to $29 \mathrm{~d}$ (ns), to 30 d GA $(P<0.05)$ ) and control groups (all $P<0.05)$ (Table 3; Figure $3 b)$.

In both the liquid-added and control groups, the PIP needed to achieve a tidal volume of $10 \mathrm{ml} / \mathrm{kg}$ after $3 \mathrm{~min}$ of ventilation was significantly higher at $27 \mathrm{~d} \mathrm{GA}(P<0.05)$ compared with the PIPs required at 29 and $30 \mathrm{~d}$ (Table 3; Figure 3c). 
Table 2. Mean (SEM) inflation rate and resistance during SI and at mid ventilation (3 min)

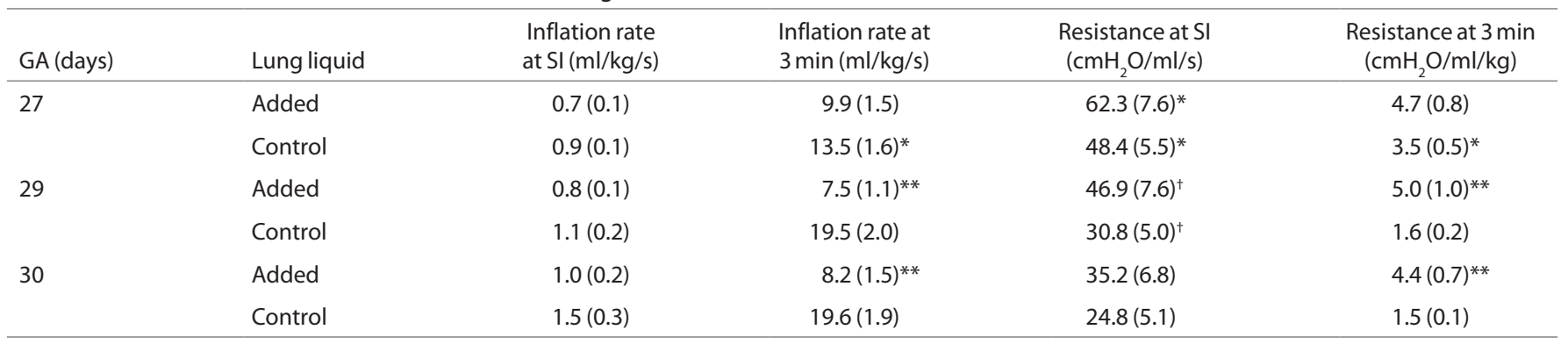

${ }^{*} P<0.0527$ vs. 29 and $30 \mathrm{~d}$ GA. ${ }^{\dagger} P<0.0529$ vs. 27 and $30 \mathrm{~d}$ GA. ${ }^{* *} P<0.01$ liquid added vs. control.

GA, gestational age; Sl, sustained inflation.
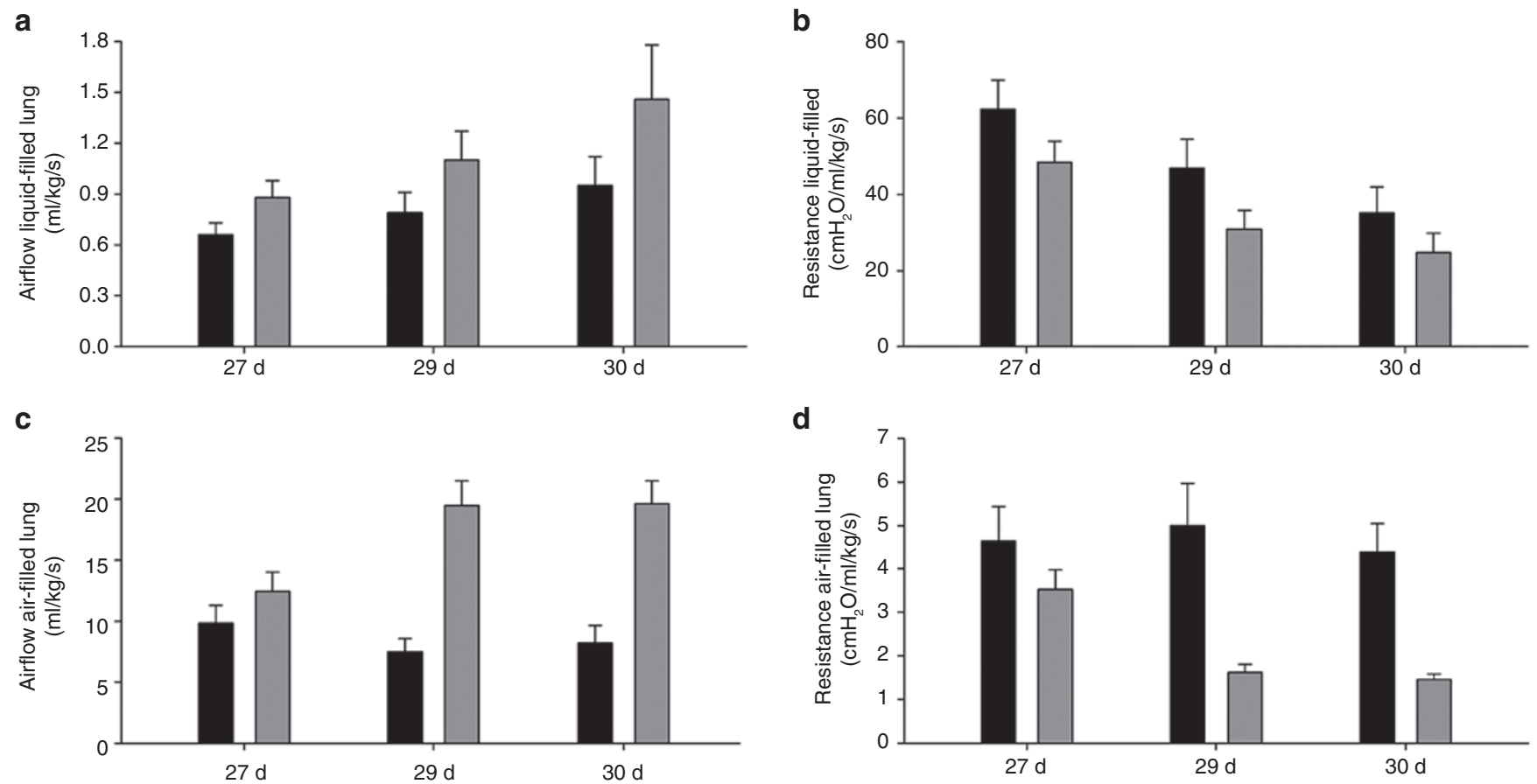

Figure 2. Airflow rates (a) into the lung and resistance of the lung (b) during the sustained inflation, that is while the airways are mostly liquid-filled, and following lung aeration (c,d) during the subsequent positive pressure ventilation period in newborn rabbits delivered at 27, 29, or $30 \mathrm{~d}$ of gestational age (GA). At each GA, airway liquid was gently aspirated and either a set volume of liquid ( $30 \mathrm{ml} / \mathrm{kg}$ ) was returned to the lung (liquid added; black) or the liquid was not replaced (control, gray).

Table 3. Mean (SEM) FRC at end of sustained inflation and PIP at end of sustained inflation and at 3 mid-ventilation ( $3 \mathrm{~min}$ )

\begin{tabular}{llccc}
\hline $\begin{array}{l}\text { GA } \\
\text { (days) }\end{array}$ & Lung liquid added & $\begin{array}{c}\text { FRC at end } \\
\mathrm{SI}(\mathrm{ml} / \mathrm{kg})\end{array}$ & $\begin{array}{c}\mathrm{FRC} \text { at } 3 \mathrm{~min} \\
(\mathrm{ml} / \mathrm{kg})\end{array}$ & $\begin{array}{c}\mathrm{PIP} \text { at } 3 \mathrm{~min} \\
\left(\mathrm{CmH}_{2} \mathrm{O}\right)\end{array}$ \\
\hline 27 & Added & $5.2(0.3)^{* *}$ & $4.3(0.6)$ & $33(1)^{*}$ \\
& Control & $2.7(0.4)^{*}$ & $2.4(1.0)^{*}$ & $30(1)^{*}$ \\
29 & Added & $6.9(0.9)^{\dagger}$ & $5.8(1.7)^{+* * *}$ & $29(1)^{* *}$ \\
& Control & $8.7(1.1)$ & $19.8(2.4)^{\dagger}$ & $22(2)^{\dagger}$ \\
30 & Added & $7.9(1.1)^{* *}$ & $12.3(1.9)^{* *}$ & $28(1)^{* *}$ \\
& Control & $11.7(1.1)$ & $26.4(1.7)$ & $17(2)$ \\
\hline
\end{tabular}

${ }^{*} P<0.0527$ vs. 29 and $30 \mathrm{~d}$ GA. ${ }^{+} P<0.0529$ vs. 27 and $30 \mathrm{~d}$ GA. ${ }^{*} P<0.01$ liquid added vs. control.

FRC, functional residual capacity; GA, gestational age; PIP, peak inspiratory pressure.

Effect of lung liquid volume. The FRC at the end of the SI was significantly greater in the liquid added group at $27 \mathrm{~d}$
$(P<0.001)$ and smaller at $30 \mathrm{~d}(P<0.05)$ when compared to the control group, but not at $29 \mathrm{~d}$ (Table 3; Figure 3a). At $27 \mathrm{~d}$ GA, the FRC measured after 3 min of ventilation was not different between the liquid-added and control groups, but at both 29 and $30 \mathrm{~d}$ GA, the FRC was significantly greater $(P<0.01$ at both ages) in the control groups compared to the liquid-added groups (Table 3; Figure 3b).

The PIP needed to achieve a tidal volume of $10 \mathrm{ml} / \mathrm{kg}$ in both liquid-added and control groups was not different at $27 \mathrm{~d}$ GA. However, the required PIP was significantly lower in the control groups compared to the liquid-added groups at both $29 \mathrm{~d}$ $(P<0.05)$ and $30 \mathrm{~d}(P<0.01)$ GA (Table 3; Figure 3c).

\section{Airway Dimensions}

Measured before the start of ventilation, airway diameters were significantly smaller in $27 \mathrm{~d}$ compared to both 29 and 


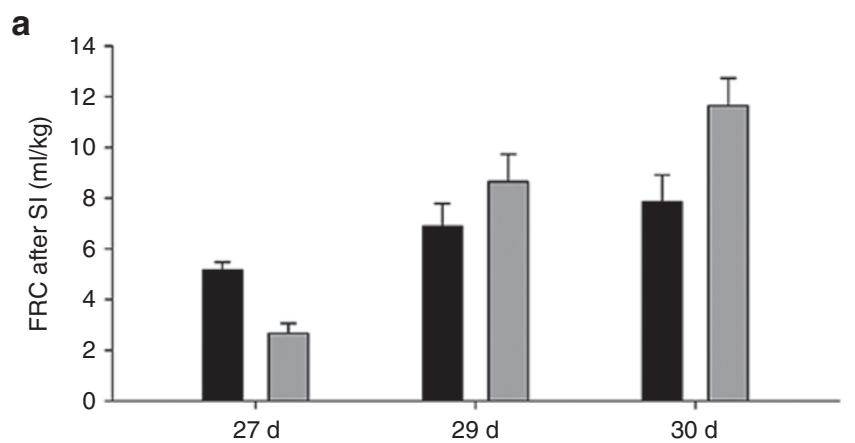

b
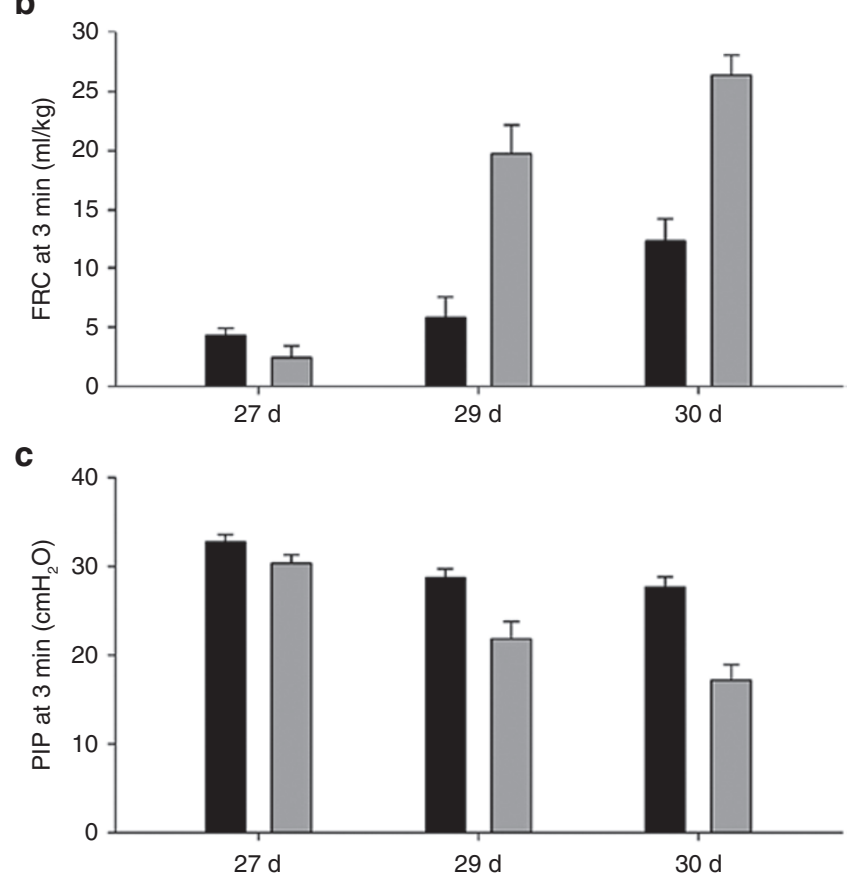

Figure 3. Functional residual capacity (FRC) immediately following the sustained inflation (SI) (a), FRC during the subsequent positive pressure ventilation period (b), and the peak inspiratory pressure required to achieve a tidal volume of $10 \mathrm{ml} / \mathrm{kg}$ (c) in newborn rabbits delivered at 27, 29 , or $30 \mathrm{~d}$ of gestational age (GA). At each GA, airway liquid was gently aspirated and either a set volume of liquid $(30 \mathrm{ml} / \mathrm{kg})$ was returned to the lung (liquid added; black) or the liquid was not replaced (control, gray).

$30 \mathrm{~d}$ GA $(P<0.05)$; dimensions were similar in 29 and $30-\mathrm{d}$ kittens (Figure 4). The diameter of the trachea increased from $1.03 \pm 0.02 \mathrm{~mm}$ at $27 \mathrm{~d}$ to $1.16 \pm 0.04 \mathrm{~mm}$ and $1.18 \pm 0.02 \mathrm{~mm}$ in 29 and $30 \mathrm{~d}$ GA respectively. Similarly, both the left $(0.76 \pm 0.03$ vs. $0.93 \pm 0.02 \mathrm{~mm})$ and right $(0.88 \pm 0.02$ vs. $1.15 \pm 0.01 \mathrm{~mm}$ ) bronchi diameters increased between 27 and $30 \mathrm{~d}$ GA (Figure 5).

During ventilation, small but highly significant changes in airway dimensions occurred, corresponding to airway pressure changes associated with lung inflation and deflation during positive pressure ventilation (Figure 6). These ventilation-induced changes were not GA dependent and were not different between control and liquid-added groups. The most notable finding was that, with each inflation, the diameter of the trachea and left bronchus increased whereas the diameter of the right bronchus decreased (Figure 6).

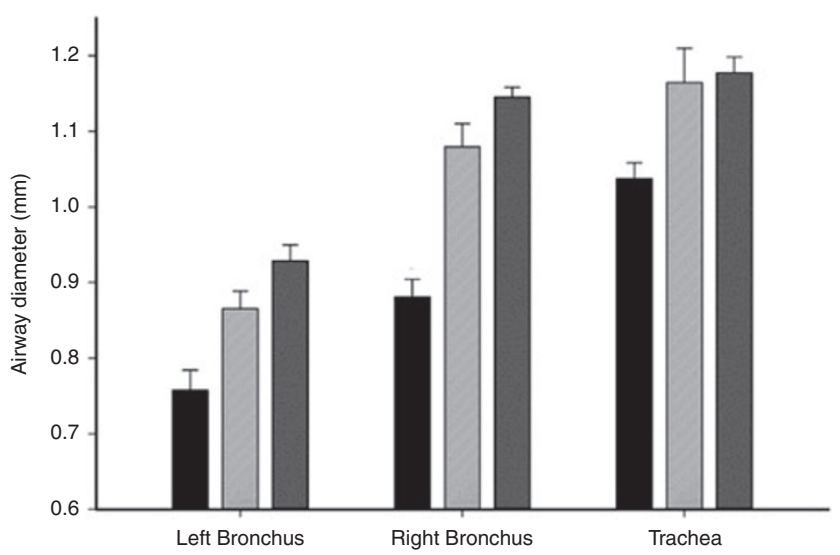

Figure 4. Diameters of the left and right bronchi and the trachea measured prior to the onset of the sustained inflation in newborn rabbits delivered at $27 \mathrm{~d}$ (black), $29 \mathrm{~d}$ (light gray), or $30 \mathrm{~d}$ (dark gray) of gestational age.

The inflation-induced increase in tracheal diameter was significantly greater during the mid-ventilation period in the liquid-added group than in the control group at all GAs $(P<0.05$; Figure $5 \mathbf{a}, \mathbf{b})$. The decrease in right bronchial diameter was greater during mid- and end-ventilation compared to immediately after the SI (significant in the control group $(P<0.05$; Figure $5 \mathrm{f})$, trend in liquid-added group (ns; Figure 5e).

\section{DISCUSSION}

Our results indicate that preterm rabbit kittens delivered at a younger GA $(27 \mathrm{~d})$ require a SI with a higher starting pressure before air will begin to flow into the lung. Furthermore, the flow of air into the lung was slower, due to a higher resistance, and so the duration of the SI needed to be longer to achieve an inflation volume of $20 \mathrm{ml} / \mathrm{kg}$ in younger compared to older kittens (29 and $30 \mathrm{~d}$ ). While the effects of elevated airway liquid volumes were restricted to increasing the required SI duration in older kittens, increased liquid volumes had a large impact on respiratory function during the iPPV period, particularly in older kittens. Most notably, it reduced airflows, increased airway resistance, reduced FRCs, and increased the PIP required to deliver a set tidal volume.

\section{Effect of GA}

The similar birth weight at 29 and $30 \mathrm{~d}$ GA was unexpected as rabbit fetuses undergo rapid growth and development in late gestation and one day usually results in significant increase in body size. It is possible that the mating time and the time of surgery on the experimental day led to a GA difference of less than $24 \mathrm{~h}$. Nevertheless, the marginal nonsignificant difference in weight likely reflects a similar developmental stage between 29 and 30d GA kittens. This likely explains the trends, but nonsignificant differences in some of the factors measured between these ages.

Our findings confirmed that kittens at $27 \mathrm{~d}$ GA have narrower airways and thus higher resistance than older kittens (29 and $30 \mathrm{~d}$ GA). As a result, they needed higher inflation pressures before air started to move distally and a longer SI before 
achieving a set inflation volume. Although the airway resistance measured can be largely accounted for by narrower airways, this resistance measurement probably also includes the resistance to liquid moving across the pulmonary epithelium, which is surface area dependent.

During iPPV, the accumulated FRC was lower and the PIP required to achieve a set tidal volume was considerably greater in younger ( $27 \mathrm{~d}$ ) compared with both older kittens. This indicates that a positive end expiratory pressure (PEEP) higher than the $5 \mathrm{cmH}_{2} \mathrm{O}$ used in this study would have been needed to maintain an appropriate FRC. Furthermore, the requirement for both higher starting SI pressures and higher PIPs to achieve a set tidal volume in younger kittens (in controls), indicates that using lower inflation pressures in more preterm infants, as currently recommended (7), needs to be re-evaluated.

\section{Effect of Lung Liquid Volume}

The volume of liquid present in the airways can vary considerably between infants (14-16). While we found that higher lung liquid volumes did not affect the SI starting pressure, they did significantly increase the required duration of the SI in both 29 and 30 d GA kittens. It is possible that a small distal gas exchange surface area is the dominant factor determining the rate of liquid movement across the epithelium in $27 \mathrm{~d}$ kittens, but this becomes less of a limiting factor in older kittens (17) and the influence of the liquid volume within the conducting airways increases and becomes the dominant factor.

Kittens with higher starting airway liquid volumes achieved similar degrees of lung aeration and therefore must have accumulated higher liquid volumes within the perialveolar interstitial lung tissue (18), leading to higher interstitial tissue pressures (19). The net effect of this is a greater trans-epithelial
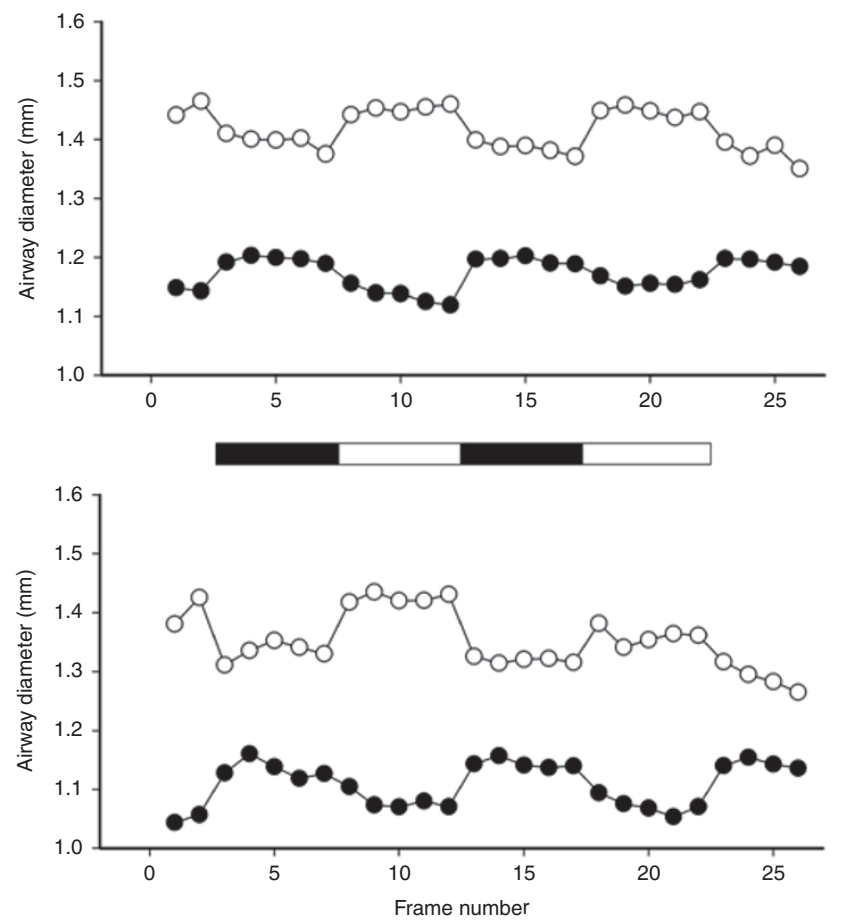

Figure 6. Two examples of the observed increase and decrease in airway diameter (mm) of the left (black circles) and right bronchus (open circles) during inflation (black line) and deflation (white line) phase of ventilation.

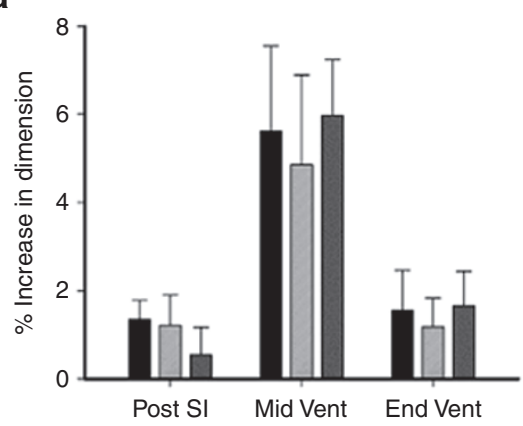

d

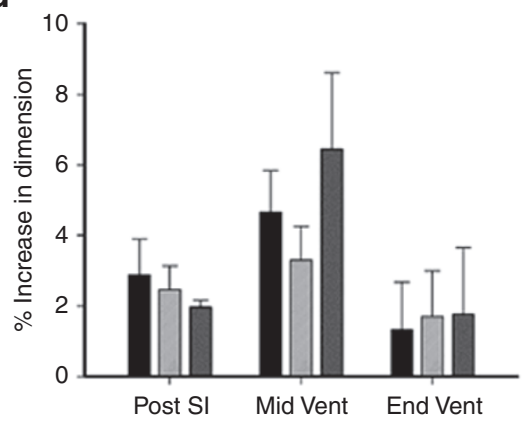

b

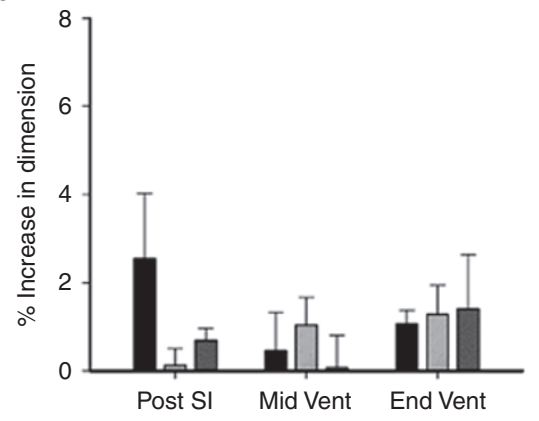

e

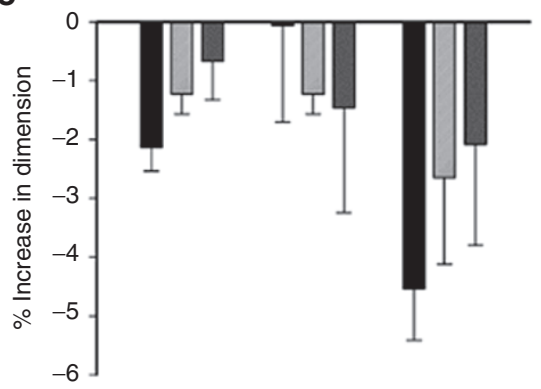

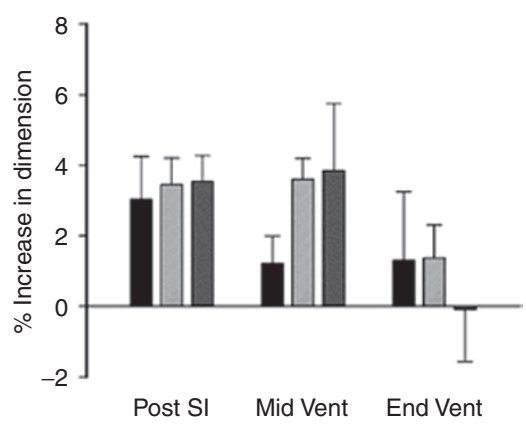

f

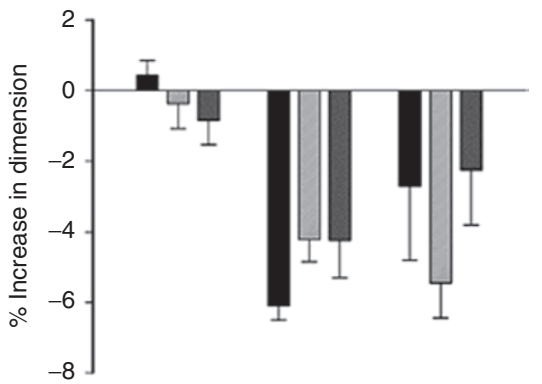

Figure 5. Percentage increase in airway diameters of the trachea $(\mathbf{a}, \mathbf{b})$ and the left $(\mathbf{c}, \mathbf{d})$ and right $(\mathbf{e}, \mathbf{f})$ bronchi that were caused by positive pressure inflations in newborn rabbits delivered at 27, 29, or $30 \mathrm{~d}$ of gestational age (GA). Values were measured immediately after the sustained inflation (post-SI), during the middle phase (mid-vent) and at the end (end vent) of the subsequent ventilation period. At each GA, airway liquid was gently aspirated and either a set volume of liquid $(30 \mathrm{ml} / \mathrm{kg}$ ) was returned to the lung (liquid added; $\mathbf{a}, \mathbf{c}, \mathbf{e})$ or the liquid was not replaced (control, $\mathbf{b}, \mathbf{d}, \mathbf{f})$. 
pressure gradient for liquid to re-enter the airways at rest (i.e., at PEEP). This likely explains the lower FRC, the higher resistance, and the larger PIP required to achieve the next tidal inflation in the liquid-added kittens at 29 and $30 \mathrm{~d}$ GA. However, this effect of higher liquid volumes is not evident in the younger 27-d kittens. We suggest that this could be one benefit of an immature lung, as a small gas exchange surface area will not only restrict liquid movement out of the airways, but will also restrict its re-entry into the airways. As such, a higher interstitial tissue pressure, caused by greater liquid accumulation within the tissue, in younger more immature kittens has little or no effect on the potential for liquid to reenter the airways at FRC.

\section{Changes in Airway Dimensions}

It is known that iPPV expands both the distal and proximal airways. The expected GA-related and liquid volume-related differences in the degree of airway expansion were not readily apparent. However, the inflation pressures used varied widely, which likely mitigated any differences. After carefully reviewing the videos, we observed that the decrease in diameter of the right bronchus resulted from rapid inflation of the right-upper lobe. This caused differential displacement of the right bronchus, whereby the lateral wall was displaced to greater degree than the medial wall, as viewed from an anterior/posterior view.

Overall, the increase in airway diameter immediately following a SI was smaller than during mid-iPPV and the volume of lung liquid did not influence this effect. We speculate that injury to the airways during ventilation at birth $(20,21)$, leading to rupture of the airways, is more likely to occur during iPPV than during a SI. However, more studies are required to verify this.

Our aim was to identify the primary factors that influence the ability of a SI to effectively aerate the lung. For this reason, kittens were ventilated via an endotracheal tube to ensure that the inflation pressure was directly applied to the airways. This necessitated that the kittens be sedated, which also reduced the variability in lung aeration associated with spontaneous breathing. This is different from the common clinical scenario, whereby the SI is usually applied via a mask. However, we have recently demonstrated the effectiveness of a SI is often hampered by mask leak and obstruction of the glottis (22). As such, our findings are only relevant to situations in which the SI can be delivered in an effective manner.

In conclusion, we have shown that younger, more immature animals required a higher starting pressure and a longer inflation time to achieve a set inflation volume of $20 \mathrm{ml} / \mathrm{kg}$ during a SI. Then during the subsequent iPPV period, the younger pups required a higher PIP and were unable to sustain an adequate FRC with a PEEP of $5 \mathrm{cmH}_{2} \mathrm{O}$. Elevated lung liquid volumes increased the required duration of the SI and reduced the FRC, increased the resistance, and increased the required PIP during the subsequent positive pressure ventilation period in older, but not in younger animals. We speculate that this is due to an increased ability for bidirectional transepithelial liquid flux in older more mature animals with a greater distal gas exchange surface area.

\section{METHODS}

All animal procedures were approved by the SPring- 8 Animal Care and Monash University's Animal Ethics Committees. All studies were conducted in experimental hutch 3 of beamline 20B2, in the Biomedical Imaging Centre at the SPring-8 synchrotron in Japan.

Pregnant New Zealand white rabbits and their kittens were used. Rabbits were healthy, sourced from and housed in the SPring- 8 Synchrotron Experimental Animal Facility in standard rabbit rooms. Animals were closely monitored and no intervention was required.

Animals must be used for these experiments because we are studying a physiological process that only occurs in live animals. As such, no alternative models exist. We used as many kittens from each doe as possible to reduce the number of rabbits required.

\section{Experimental Procedure}

The procedure has been described in detail in previous publications $(23,24)$. Fetal rabbits were delivered by cesarean section at 27,29 , and $30 \mathrm{~d}$ GA (term $\approx 32 \mathrm{~d}$, at 27, 29, $30 \mathrm{~d}$ the lungs are functionally equivalent to humans at approximately 24,28 , and $32 \mathrm{wk}$ of gestation) and sedated with sodium pentobarbitone (Nembutal; $0.1 \mathrm{mg}$ i.p.). The umbilical cord remained intact and the kitten's head was covered with fetal membranes while a blocked endotracheal tube (18G intracath) was inserted via tracheostomy. After placement of the endotracheal tube, as much airway liquid as possible was gently withdrawn using a $1 \mathrm{ml}$ syringe attached to the endotracheal tube and the amount measured. At each GA, kittens were randomized to two groups. In one group (volume added), $30 \mathrm{ml} / \mathrm{kg}$ of $\mathrm{NaCl} 0.9 \%$ (expected resting lung volume (25)) was added back into the airways, whereas no volume was added to the control group.

\section{Ventilation Protocol}

Following delivery, the kitten was immediately placed, head out, in a warmed $\left(40{ }^{\circ} \mathrm{C}\right)$ water-filled plethysmograph (custom-made) located within the experimental imaging hutch $(26,27)$ and connected to a purpose-built pressure-limited ventilator as previously described (28). Following imaging onset, ventilation commenced with an initial $\mathrm{SI}$ of $22 \mathrm{cmH}_{2} \mathrm{O}$, which increased by $2 \mathrm{cmH}_{2} \mathrm{O}$ steps every $3 \mathrm{~s}$ until air began to flow into the lung; this was indicated as an increase in gas volume measured using the plethysmograph. At this point, the inflation pressure was held constant, but SI continued until a volume of $20 \mathrm{ml} / \mathrm{kg}$ of air had entered the lung; this volume equates to $15 \mathrm{ml} /$ $\mathrm{kg}$ of FRC, plus a tidal volume of $5 \mathrm{ml} / \mathrm{kg}$. Once $20 \mathrm{ml} / \mathrm{kg}$ had entered the lung, the SI was terminated and ventilation continued with iPPV, starting with a peak inflation pressure (PIP) equivalent to the final pressure used for the SI. The PEEP was set at $5 \mathrm{cmH}_{2} \mathrm{O}$ and the inspiratory and expiratory times were set at $1 \mathrm{~s}$. The PIP was adjusted to generate a tidal volume of $10 \mathrm{ml} / \mathrm{kg}$. Ventilation continued for $7 \mathrm{~min}$ during which airway pressures and lung gas volumes (from the plethysmograph) were digitally recorded (Powerlab, ADInstruments; Sydney, Australia) and images acquired. All animals were humanely killed at the conclusion of the experiment with Nembutal (>100 mg/ $\mathrm{kg}$ ) administered i.v. (doe) or i.p. (kittens).

\section{Plethysmography}

Prior to experimentation, the plethysmograph was calibrated. From the plethysmograph, we determined the pressure at which air started to flow into the lung and measured the rate of volume increase, the duration of the SI and the maximum lung volume at end of SI $(\sim 20 \mathrm{ml} / \mathrm{kg})$, which was truncated manually. We also measured airflow and calculated respiratory system resistance from these recordings as well as FRC, averaged over three inflations, at end of SI and after $3 \mathrm{~min}$ of iPPV.

Image Acquisition has been described in detail previously (see ref. (29)). Image acquisition was synchronized with ventilation. The onset of inflation triggered the camera to acquire a sequence of nine images at $5 \mathrm{~Hz}$. All images were captured using a $30 \mathrm{~ms}$ exposure time. Five images were acquired during inspiration and four during expiration. Image sequences were used to confirm that the lung was fully aerated at the end of the SI and to calculate lung gas volumes at peak inflation and at FRC (29). 


\section{Sample Size}

To detect the minimal biologically significant difference in ventilation with a coefficient of variation of $\sim 25 \%$, we require $\sim 7$ animals per group, assuming an $\alpha$ value of 0.05 and a power of $>0.8$.

\section{Statistical Analysis}

Results are presented as means \pm SEM. A $P$ value of $<0.05$ was considered statistically significant. Starting pressure, duration SI, lung volume at end SI, FRC, resistance, air flow, and the airway diameter were analyzed using a one-way ANOVA with a Tukey post-hoc test for parametric values and a Kruskal-Wallis $H$-test with a Mann-Whitney $U$-post-hoc test for nonparametric values.

\section{SUPPLEMENTARY MATERIAL}

Supplementary material is linked to the online version of the paper at http:// www.nature.com/pr

\section{ACKNOWLEDGMENTS}

The authors gratefully acknowledge the support provided by the SPring-8 synchrotron facility (Japan), which was granted by the SPring-8 Program Review Committee, for providing access to the $\mathrm{X}$-ray beamline and associated facilities. This research was supported by National Institute of Health R01HD072848-01A1.

\section{STATEMENT OF FINANCIAL SUPPORT}

This research was supported by the Australian Research Council, the Australian National Health and Medical Research Council and the Victorian Government's Operational Infrastructure Support Program. We acknowledge travel funding provided by the International Synchrotron Access Program (ISAP) managed by the Australian Synchrotron and funded by the Australian Government. M.J.K. and A.F. are the recipients of ARC Australian Research Fellowship (DP110101941) and NHMRC Career Development Fellowships respectively. A.B.te P. is recipient of a Veni-grant, The Netherlands Organisation for Health Research and Development (ZonMw), part of the Innovational Research Incentives Scheme Veni-Vidi-Vici project number 91612027.

Disclosure: No competing interest, financial or otherwise, is declared by all authors.

\section{REFERENCES}

1. te Pas AB, Siew M, Wallace MJ, et al. Establishing functional residual capacity at birth: the effect of sustained inflation and positive end-expiratory pressure in a preterm rabbit model. Pediatr Res 2009;65:537-41.

2. te Pas AB, Siew M, Wallace MJ, et al. Effect of sustained inflation length on establishing functional residual capacity at birth in ventilated premature rabbits. Pediatr Res 2009;66:295-300.

3. Sobotka KS, Hooper SB, Allison BJ, et al. An initial sustained inflation improves the respiratory and cardiovascular transition at birth in preterm lambs. Pediatr Res 2011;70:56-60.

4. Klingenberg C, Sobotka KS, Ong T, et al. Effect of sustained inflation duration; resuscitation of near-term asphyxiated lambs. Arch Dis Child Fetal Neonatal Ed 2013;98:F222-7.

5. Wallace MJ, Zahra V, e Pas AB, iew M, llison BJ, ooper SB. A sustained inflation at birth reduces markers of lung injury. J Paediatr Child Health 2015;48:8-81.

6. Hillman NH, Kemp MW, Noble PB, Kallapur SG, Jobe AH. Sustained inflation at birth did not protect preterm fetal sheep from lung injury. Am J Physiol Lung Cell Mol Physiol 2013;305:L446-53.

7. Wyckoff MH, Aziz K, Escobedo MB, et al. Part 13: Neonatal resuscitation: 2015 American Heart Association guidelines update for cardiopulmonary resuscitation and emergency cardiovascular care. Circulation 2015;132(18 Suppl 2):S543-60.

8. Wyllie J, Perlman JM, Kattwinkel J, et al.; Neonatal Resuscitation Chapter Collaborators. Part 7: Neonatal resuscitation: 2015 International Consensus on cardiopulmonary resuscitation and emergency cardiovascular care science with treatment recommendations. Resuscitation 2015;95:e169-201.

9. Vyas H, Milner AD, Hopkin IE, Boon AW. Physiologic responses to prolonged and slow-rise inflation in the resuscitation of the asphyxiated newborn infant. J Pediatr 1981;99:635-9.

10. Harling AE, Beresford MW, Vince GS, Bates M, Yoxall CW. Does sustained lung inflation at resuscitation reduce lung injury in the preterm infant? Arch Dis Child Fetal Neonatal Ed 2005;90:F406-10.
11. te Pas AB, Walther FJ. A randomized, controlled trial of delivery-room respiratory management in very preterm infants. Pediatrics 2007;120: 322-9.

12. Lindner W, Högel J, Pohlandt F. Sustained pressure-controlled inflation or intermittent mandatory ventilation in preterm infants in the delivery room? A randomized, controlled trial on initial respiratory support via nasopharyngeal tube. Acta Paediatr 2005;94:303-9.

13. Lista G, Boni L, Scopesi F, et al.; SLI Trial Investigators. Sustained lung inflation at birth for preterm infants: a randomized clinical trial. Pediatrics 2015;135:e457-64.

14. te Pas AB, Davis PG, Hooper SB, Morley CJ. From liquid to air: breathing after birth. J Pediatr 2008;152:607-11.

15. Hooper SB, Siew ML, Kitchen MJ, te Pas AB. Establishing functional residual capacity in the non-breathing infant. Semin Fetal Neonatal Med 2013;18:336-43.

16. van Vonderen JJ, Roest AA, Siew ML, Walther FJ, Hooper SB, te Pas AB. Measuring physiological changes during the transition to life after birth. Neonatology 2014;105:230-42.

17. Alcorn DG, Adamson TM, Maloney JE, Robinson PM. A morphologic and morphometric analysis of fetal lung development in the sheep. Anat Rec 1981;201:655-67.

18. Bland RD. Loss of liquid from the lung lumen in labor: more than a simple "squeeze". Am J Physiol Lung Cell Mol Physiol 2001;280:L602-5.

19. Miserocchi G, Poskurica BH, Del Fabbro M. Pulmonary interstitial pressure in anesthetized paralyzed newborn rabbits. J Appl Physiol (1985) 1994;77:2260-8.

20. Hillman NH, Kallapur SG, Pillow JJ, et al. Airway injury from initiating ventilation in preterm sheep. Pediatr Res 2010;67:60-5.

21. Jobe AH, Hillman N, Polglase G, Kramer BW, Kallapur S, Pillow J. Injury and inflammation from resuscitation of the preterm infant. Neonatology 2008;94:190-6.

22. van Vonderen JJ, Hooper SB, Hummler HD, Lopriore E, te Pas AB. Effects of a sustained inflation in preterm infants at birth. J Pediatr 2014;165: 903-8.e1.

23. Kitchen MJ, Siew ML, Wallace MJ, et al. Changes in positive end-expiratory pressure alter the distribution of ventilation within the lung immediately after birth in newborn rabbits. PLoS One 2014;9:e93391.

24. Siew ML, Wallace MJ, Allison BJ, et al. The role of lung inflation and sodium transport in airway liquid clearance during lung aeration in newborn rabbits. Pediatr Res 2013;73(4 Pt 1):443-9.

25. Hooper SB, Harding R. Fetal lung liquid: a major determinant of the growth and functional development of the fetal lung. Clin Exp Pharmacol Physiol 1995;22:235-47.

26. Hooper SB, Kitchen MJ, Wallace MJ, et al. Imaging lung aeration and lung liquid clearance at birth. FASEB J 2007;21:3329-37.

27. Siew ML, Te Pas AB, Wallace MJ, et al. Positive end-expiratory pressure enhances development of a functional residual capacity in preterm rabbits ventilated from birth. J Appl Physiol (1985) 2009;106:1487-93.

28. Kitchen MJ, Habib A, Fouras A et al. A new design for high stability pressure-controlled ventilation for small animal lung imaging. Journal of Instrumentation 2010;5: T02002.

29. Kitchen MJ, Lewis RA, Morgan MJ, et al. Dynamic measures of regional lung air volume using phase contrast $\mathrm{x}$-ray imaging. Phys Med Biol 2008;53:6065-77.

(c) (1) $\Theta($ This work is licensed under a Creative Commons Attribution-NonCommercial-NoDerivs $\quad \mathbf{4 . 0}$ International License. The images or other third party material in this article are included in the article's Creative Commons license, unless indicated otherwise in the credit line; if the material is not included under the Creative Commons license, users will need to obtain permission from the license holder to reproduce the material. To view a copy of this license, visit http://creativecommons.org/ licenses/by-nc-nd/4.0/

(C) AB. te Pas et al. (2016) 